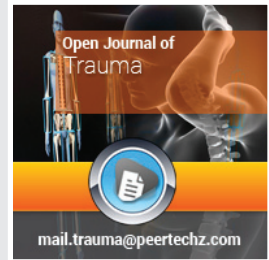

Clinical Group

\title{
Open Journal of Trauma
}

Celia Y Quang, Ryan 0 Kennedy, Scott G Blair, Sidney B Brevard and Jon D Simmons*

Division Acute Care Surgery and Burns, The University of South Alabama Medical Center, Mobile, $A L$, USA

Dates: Received: 21 December, 2016; Accepted: 02 January, 2017; Published: 03 January, 2017

*Corresponding author: Jon D Simmons, M.D. Associate Professor, University of South Alabama, Division of Acute Care Surgery and Burns, 2451 Fillingim St., Suite 10-I, Mobile, AL 36617-2293, USA, E-mail: jdsimmons@health.southalabama.edu

https://www.peertechz.com

\section{Case Report}

\section{Is There a Clinical Difference between Salt Water and Fresh Water Drowning?}

\section{Abstract}

Introduction: Salt water near-drowning events are not uncommon in coastal regions. The difference in tonicity between salt and fresh water in near-drowning events leads many to believe there should be differences in the approach to managing the patient. We present a case of near-drowning in salt water and a thorough review of the literature in managing these patients.

Case Presentation: A sixteen year old male presented to our level 1 trauma center approximately 30 minutes after a near-drowning in salt water. The patient began to develop hypoxemia associated with profound pulmonary edema that was not responsive to elevated inspired oxygen levels and high levels of positive end-expiratory pressure (PEEP).

Conclusion: Despite the alterations in the alveolar interface that are dependent on the tonicity of the fluid, the ultimate treatment of drowning injuries remains consistent regardless of the tonicity of the water. Aggressive therapy, tailored to the individual patient, can improve pulmonary shunting. Patients with hypoxemia requiring intubation should be ventilated with (PEEP) as animal studies have shown rapid improvements in $\mathrm{PaO} 2$ with PEEP values in the range of 5-15.

\section{Introduction}

Salt water near-drowning events are not uncommon in coastal regions. The difference in tonicity between salt and fresh water in near-drowning events leads many to believe there should also be differences in the approach to managing the patient. We present a case of near-drowning in salt water and a thorough review of the literature to determine if there should be a difference in the way in which patients are managed with near fresh or salt water drownings.

\section{Case Presentation}

A sixteen year old male presented to our level 1 trauma center approximately 30 minutes after a near-drowning in salt water. The patient was initially in cardiac arrest but was successfully resuscitated at the scene. Upon arrival, the patient was hemodynamically stable, hypothermic, and unconscious. The standard trauma diagnostic testing did not reveal an injury. However, CT of the brain did reveal diffuse cerebral edema consistent with hypoxic brain injury and CT of the chest was consistent with aspiration (Figure 1). The initial arterial blood gas revealed adequate oxygenation (pO2 $340 \mathrm{mmHg}$ ) and ventilation ( $\mathrm{pCO} 242 \mathrm{mmHg}$ ). The patient was admitted to the Surgical Intensive Care Unit for re-warming and supportive care. After approximately four hours, the patient began to develop hypoxemia (pO2 $40 \mathrm{mmHg}$ ) and hypercarbia (pCO2 88 $\mathrm{mmHg}$ ) associated with profound pulmonary edema (Figure 2 ). The hypoxemia was not responsive to elevated inspired oxygen levels and high levels of PEEP. Copious amounts of frothy edema fluid were frequently aspirated from the patient's airway. Brain death was confirmed on hospital day four.

\section{Discussion}

Public perception regarding drowning includes the misconception that large quantities of water are aspirated, preventing ventilation and oxygenation. However, retrospective

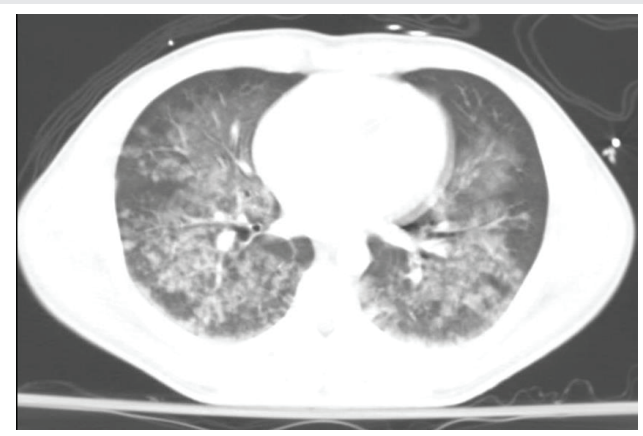

Figure 1: Initial chest CT demonstrating diffuse alveolar densities consistent with an drowning event. 


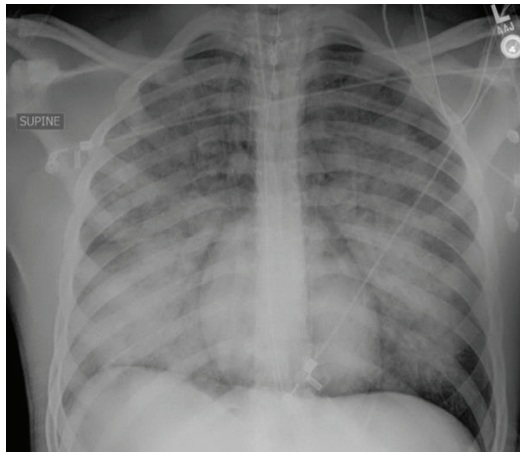

Figure 2: Chest X-ray demonstrating diffuse pulmonary edema.

autopsy reviews reveal that only a small percentage of fatal drownings are found to have large quantities of intraalveolar fluid. The pathological insult is primarily due to the development of a non-physiologic air/liquid interface. The physiologic response when faced with this alteration is an involuntary laryngospasm. This prevents the exchange of gasses necessary for ventilation and oxygenation. As hypoxia and hypercarbia worsen, the ultimate outcome is cardiac arrest.

Traditional teaching represents a consensus that drowning in hypertonic solution (such as the sea water seen in our patient) with subsequent aspiration, results in pulmonary edema due to the large increase in osmolar gradients. Conversely, aspiration of fresh water has shown to cause a dilution effect of surfactant in the alveoli, with subsequent decrease in surface tension and collapse of the alveoli [1]. This decrease in surfactant is the nidus for alveolar collapse and development of ARDS. However, no role for the use of surfactant treatment of ARDS has been demonstrated [2]. Animal studies reveal that direct injury to the alveoli is the most severe in fresh water solution, with hypertonic and isotonic saline solutions causing less damage [3]. Regardless of medium, the disruption of the $\mathrm{P}(\mathrm{A}-\mathrm{a}) \mathrm{O} 2$ gradient and the resulting pulmonary shunting results in the hypoxemia, hypercarbia, and acidosis. There are several methods that can be utilized to help improve the hypoxemia associated with severe ARDS secondary to drowning. Both prone positioning [4] and extracorporeal membrane oxygenation (ECMO) [5] have been demonstrated to improve oxygenation and decreased mortality.

A 1983 animal study by Yammamato utilizing rats submersed in hypertonic saline, isotonic saline, and fresh water, showed no difference in survival time. The hypertonic saline group did have the highest levels of fluid within the lung tissues, and these subjects were noted to produce frothy secretions in greater frequency than the other subjects [6]. Case reports from Cohen in 1992 utilized sampling of alveolar fluid in non-fatal drowning patients and showed that despite the initial hyperosmolarity of the sea water solution (926mOsm), equilibration of the osmolar gradient was achieved within 4 hours of admission [7]. The mechanism by which this is restored is through a Na,K-ATPase, as demonstrated in both in situ and in vivo animal models, to actively restore the alveoli to their normal tonicity [8]. Aspiration and suction of the edema that is associated with hypertonic drowning must be weighed against disruption of oxygenation and ventilation, as the pulmonary shunting is usually short-term and self-limited.

\section{Conclusion}

Despite the alterations in the alveolar interface that are dependent on the tonicity of the fluid, the ultimate treatment of near-drowning injuries remains consistent regardless of the tonicity of the water. Aggressive therapy, tailored to the individual patient, can improve pulmonary shunting. Patients with hypoxemia requiring intubation should be ventilated with positive end-expiratory pressure (PEEP) as animal studies have shown rapid improvements in $\mathrm{PaO} 2$ with $\mathrm{PEEP}$ values in the range of 5-15 [9-12].

\section{References}

1. Giammona ST, Modell JH (1967) Drowning by total immersion. Effects on pulmonary surfactant of distilled water, isotonic saline and sea water. Am J Dis Child 114: 612-616. Link: https://goo.gl/xdh8y6

2. Anzueto A, Baughman RP, Guntupalli KK, Weg Jg, Wiedemann HP, et al. (1996) Aerosolized surfactant in adults with sepsis-induced acute respiratory distress syndrome. Exosurf Acute Respiratory Distress Syndrome Group. N Engl J Med 334: 1417-1421. Link: https://goo.gl/SeJPFp

3. Orlowski, JP, Abulleli MM, Philips JM (1987) Effects of tonicities of saline solutions on pulmonary injury on drowning. Crit Care Med 15: 126-130. Link: https://goo.gl/ISiwyn

4. Tulleken JE, van der Werf TS, Ligtenberg JJ, Fijen JW, Zijlstra JG (1999) Prone position in a spontaneously breathing near-drowning patient. Intensive Care Med 25: 1469-1470. Link: https://goo.gl/eadCrC

5. Kim KI, Lee WY, Kim HS, Jeong JH, Ko HH (2014) Extracorporeal membrane oxygenation in near-drowning patients with cardiac or pulmonary failure. Scand J Trauma Resusc Emerg Med 22: 77. Link: https://goo.gl/3M9oX2

6. Yammamato $K$ (1983) The effects of drowning media on the lung water content. An experimental study on rats. Z Rechtsmed. 90: 1-6. Link: https:// goo.gl/OuGp76

7. Cohen DS1, Matthay MA, Cogan MG, Murray JF (1992) Pulmonary edema associated with salt water near-drowning: new insights. The Am Rev Respir Dis 146:794-796. Link: https://goo.gl/ORdDjQ

8. Matthay MA, Folkesson HG, Verkman AS (1996) Salt and water transport across alveola and distal airway epithelia in the adult lung. Am J Physiol 270: L487-503. Link: https://goo.gl/vX4OZI

9. Bergquist RE, Vogelhut MM, Modell JH, et al. (1980) Comparison of ventilatory patterns in the treatment of fresh water near-drowning in dogs. Anesthesiology 52: 142-148. Link: https://goo.gl/j2GOzo

10. Oehmichen M, Henning R, Meissner $C$ (2008) Near-drowning and clinical laboratory changes. Leg med (Tokyo) 10: 1-5. Link: https://goo.gl/4buAnc

11. Lee KH (1998) A retrospective study of near-drowning victims admitted to the intensive care unit. Ann Acad Med Singapore 27: 344-346. Link: https:// goo.gl/orK6bl

12. Guerin C, Reignier J, Richard JC, Beuret P, Gacouin A, et al. (2013) Prone positioning in severe acute respiratory distress syndrome. N Engl J Med 368: 2159-2168. Link: https://goo.gl/QFIWCh 